\title{
La Gestión de Recursos Leñosos por Cazadores- Recolectores Transicionales en los Sectores Intermedios de Antofagasta de la Sierra (Catamarca, Argentina): El Caso de Alero Sin Cabeza
}

\author{
Woody Resource Management by Transitional Hunter-Gatherers \\ at Intermediate Sectors of Antofagasta de la Sierra (Catamarca, \\ Argentina): The Case of Alero Sin Cabeza
}

Patricia Escola ${ }^{\mathrm{I}}$, María Gabriela Aguirre ${ }^{\mathrm{II}}$ y Salomón Hocsman ${ }^{\mathrm{III}}$

\begin{abstract}
RESUMEN
El estudio de carbones procedentes de contextos arqueológicos ha recibido una creciente atención desde mediados del siglo XX debido a las interpretaciones generadas en diferentes investigaciones. En este trabajo se presentan los resultados del análisis del registro antracológico correspondiente a ocupaciones de cazadores-recolectores transicionales del sitio Alero Sin Cabeza, fechadas en ca.3500 años AP. Al respecto, interesa la gestión de los recursos vegetales y, particularmente, el aprovisionamiento de las materias primas leñosas. Los resultados obtenidos señalan el empleo de combustibles leñosos locales de diferentes especies, predominando el taxa Adesmia sp. que incluye a leñas con buenas propiedades combustibles. Se plantea el uso del Tolar y Campo como espacios principales de aprovisionamiento leñoso y la articulación con espacios más alejados, como el Pajonal. Se propone que durante las ocupaciones cazadorasrecolectoras transicionales del sitio se priorizaron las recolecciones en las inmediaciones del alero al mismo tiempo que se llevaron a cabo recolecciones complementarias de leña en sectores algo más lejanos. Esto estaría en concordancia con la ocurrencia de movilidad residencial reducida hacia los 3500 años AP.

Palabras Clave: Antracología, Recursos Leñosos, Gestión, Cazadores-Recolectores Transicionales, Puna Argentina
\end{abstract}

\begin{abstract}
This paper presents the results of the analysis of charcoal record corresponding to transitional hunter-gatherer occupations of the Alero Sin Cabeza site, dated ca. 3500 years BP. We are interested in ancient management practices of plant resources and, particularly, the supply of woody raw materials. The results indicate the use of different wood fuel local species, predominating taxa Adesmia sp. a firewood with good fuel properties. We propose the use of Tolar and Campo as main woody procurement areas, as well as the articulation with more remote areas, such as Pajonal. It is proposed that during hunter-gatherer transitional occupations of this site, forage for woody materials prioritized near-site areas, complemented with firewood collections conducted in more distant areas. This is consistent with the occurrence of reduced residential mobility around 3500 years BP.
\end{abstract}

Key Words: Anthracology, Woody Resources, Management, Transitional Hunter-Gatherers, Argentinian Puna

CONICET - Escuela de Arqueología (UNCa) Maximio Victoria S/N ${ }^{\circ}$ Predio Universitario. San Fernando del Valle de Catamarca. CP 4700. Correo-e: patoescola@hotmail.com

ii Facultad de Ciencias Naturales e Instituto Miguel Lillo (Universidad Nacional de Tucumán). Miguel Lillo 205 (4000) San Miguel de Tucumán, Tucumán, Argentina. Correo-e: mgabaguirre@hotmail.com

iii CONICET. Instituto Superior de Estudios Sociales (CONICET-UNT) - Instituto de Arqueología y Museo (FCN e IML, UNT). San Lorenzo 429 (4000) San Miguel de Tucumán, Tucumán, Argentina. Correo-e: shocsman@hotmail.com

Recibido: 26 de marzo de 2013. Revisado: 09 de mayo de 2013. Aceptado: 28 de mayo de 2013. 


\section{INTRODUCCIÓN}

El desarrollo de las sociedades humanas está estrechamente ligado al uso del fuego. Desde el momento en que la especie humana ha sido la única que ha conseguido domesticarlo su importancia cultural ha sido largamente apreciada desde la prehistoria (Jardón Giner 1998). De este modo, el fuego y su uso a lo largo de la historia del Hombre se convirtieron en temas de interés para diferentes disciplinas.

Desde una perspectiva arqueológica, el estudio de las actividades relacionadas con el uso del fuego se sustenta en el análisis de los contextos de las áreas de combustión, el análisis de la micro-morfología del suelo termoalterado, de restos orgánicos, de restos de combustible, de rocas termoalteradas y demás sustancias y objetos que pudieron quedar contenidos en dichas áreas (March y Ferrari 1989; March et al. 1991; Soler Mayor 2003). Por otra parte, existen restos de combustión no estructurados definidos por aquellos elementos residuales (cenizas, restos orgánicos termo-alterados, restos de artefactos termo-alterados) interconectados con las propias estructuras de combustión in situ (Soler Mayor 2003). Al respecto, son importantes también aquellos restos de carbón que se presentan dispersos en los niveles arqueológicos debido a la acción de agentes naturales o antrópicos (Badal et al. 2003).

Los estudios antracológicos llevados a cabo hasta el momento en la localidad de Antofagasta de la Sierra (Catamarca, Argentina) -en adelante, ANS- permitieron identificar diversas especies leñosas utilizadas como combustible, el radio de captación de las mismas y las asociaciones vegetales de las cuales proceden (Rodríguez 1999, 2000; Aguirre 2007, entre otros). En este trabajo presentamos los resultados obtenidos a través del análisis del registro antracológico correspondiente a ocupaciones de cazadoresrecolectores transicionales del sitio Alero Sin Cabeza, fechadas en ca. 3500 años AP. Este sitio se encuentra ubicado en el sector aterrazado superior del curso inferior del río Miriguaca, en los Sectores Intermedios de la cuenca. A diferencia de otras quebradas de la microrregión de ANS, la quebrada del río Miriguaca ha sido poco estudiada desde una perspectiva arqueobotánica, por lo que este trabajo es un aporte al desarrollo de dicha línea de investigación en este sector del área como así también a nivel regional. En este sentido, consideramos que se contribuye al conocimiento sobre la movilidad de grupos cazadores-recolectores en momentos transicionales.

Este trabajo se aborda desde la perspectiva de la gestión de los recursos vegetales, es decir, el modo o manera históricamente situado que los grupos 
humanos han obtenido, transformado y consumido estos recursos (Piqué i Huerta 1999, Asouti y Hather 2001) a fin de poder caracterizar la relación entre el Hombre y su entorno, superando la sola elaboración de listados de especies utilizadas en el pasado. Al respecto, interesa particularmente el aprovisionamiento de las materias primas leñosas en este sector de la cuenca de Antofagasta de la Sierra ya que esto permitirá reforzar mediante una vía independiente evidencias de cambios en el rango de acción de los grupos recuperadas en otros sitios de este sector.

\section{ANTRACOlOGÍA Y GESTIÓN DE LOS RECURSOS LEÑOSOS}

El término Antracología proviene etimológicamente de la palabra griega ántraxakos que significa "carbón ardiente" (Euba Rementeria 2008). El carbón puede ser el resultado de acciones humanas con fines domésticos o industriales y es producido también en la naturaleza como resultado de incendios naturales y de la actividad volcánica (Scott y Damblon 2010). $\mathrm{Al}$ ser este elemento el producto de fenómenos naturales y culturales, distintas disciplinas se han interesado a lo largo del tiempo en el estudio de los procesos de formación del carbón. Al respecto, se han realizado estudios desde la perspectiva de la ecología de los ecosistemas (Conedera et al. 2009), como también estudios asociados a los cambios físicos (Prior y Alvin 1983) y químicos (Mc Parland et al. 2010) que sufren los leños luego de la combustión. Además, el carbón ha demostrado ser un tipo de material útil para abordar temas relacionados a estudios paleoambientales (Whitlock y Bartlein 2003; Willis et al. 2008; Blarquez y Carcaillet 2010; Marconetto 2010; Grant y Waller 2010) y a la reconstrucción de la vegetación en el pasado (Asouti y Hather 2001).

Es posible identificar en la literatura arqueológica diferentes definiciones del término Antracología (Pique i Huerta y Pique i Huerta 1991; Scheel-Ybert 2004), Solari (2007: 130) la considera como el "estudio de las maderas carbonizadas procedentes de sitios arqueológicos o naturales, siendo su interés la relación entre las comunidades humanas y el medio vegetal leñoso, la antracología es capaz de establecer un continuo entre el uso del ambiente por las comunidades actuales y la percepción arqueológica que de este uso se hizo en el pasado". Particularmente, adherimos a esta definición ya que conjuga el estudio de las maderas carbonizadas y el interés como arqueólogos por reconstruir las distintas formas en que los grupos humanos establecieron relaciones con el mundo vegetal. En este sentido, la naturaleza es apropiada por los individuos, es transformada y explotada 
según sus capacidades (Piqué i Huerta 1999). Así, el mundo vegetal es explotado y transformado por la sociedad a través de acciones deliberadas. Los elementos vegetales que integran una determinada comunidad vegetal pueden ser empleados o no en la subsistencia; en tal sentido, la distinción entre recursos naturales y recursos sociales es importante ya que el concepto de recurso social designa a aquellos recursos que existen en el entorno y son sistemáticamente incorporados a una actividad social en una época y lugar específicos (Mameli 2003). Realizar este tipo de distinciones nos permite realizar una catalogación de los recursos sociales a través de la identificación de los mismos en el registro arqueológico y establecer cuáles han sido los recursos sociales que tuvieron un papel para los grupos humanos que ocuparon el área de estudio hacia los 3500 años AP.

Berihuete Azorín y Piqué (2006) señalan que la obtención de recursos vegetales realizada principalmente a través de la recolección, requiere de saberes que involucran el conocimiento del ciclo vegetativo de las plantas, su período de floración y las áreas de distribución. Así, el concepto de gestión de recursos vegetales corresponde a la manera o modo históricamente determinado en que los grupos humanos han obtenido, transformado y consumido estos recursos (Piqué i Huerta 1999; Marconetto 2005; Berihuete Azorín y Piqué 2006). De este modo, corresponde a la actuación que la sociedad ejerce sobre los recursos vegetales del medio ambiente.

En el caso de las estrategias de gestión de recursos forestales, Piqué i Huerta (1999) considera que la producción de energía derivada de los combustibles leñosos, consiste en energía obtenida mediante la articulación de diversos procesos de trabajo que configuran secuencias productivas. En este sentido, los procesos de trabajo implicados son: a) el aprovisionamiento de las materias primas leñosas, que implica la transformación de la materia prima en materias primas necesarias; b) la gestión de los productos que implica la distribución de los mismos, la adecuación a las necesidades sociales y, en algunos casos, el almacenamiento; c) el proceso de producción de energía, que implica la transformación de las materias primas leñosas en energía a través de la combustión; d) la integración de los diferentes tipos de energía (calórica, lumínica) en otros procesos de trabajo; y e) la reubicación de los residuos generados a través de los procesos de trabajo implicados en el mantenimiento de las áreas de combustión y del espacio social. En este trabajo se explora principalmente el aprovisionamiento de las materias primas leñosas, considerando que éste es un trabajo inicial para la quebrada en estudio. 
En los desiertos de altura, como es el caso de Antofagasta de la Sierra, los recursos leñosos pueden considerarse recursos críticos porque están sujetos a variaciones ambientales frecuentes (impredecibles y de corto plazo) y a la acción antrópica. Por ejemplo, en el área de estudio, actualmente, la sobreexplotación de algunas especies leñosas en los alrededores de la villa de Antofagasta de la Sierra habría ocasionado la desaparición de las mismas (Olivera 2006).

La leña se capta como recurso inerte ya que para ser consumida debe estar seca. Por esto, debe, en realidad, concebirse como un recurso muerto o abiótico y no como un recurso biótico (Allué y García Antón 2006). En mayor o menor medida, todas las partes de las plantas tienen propiedades combustibles. El fuego afecta a todas las diferentes formas de vida, tanto a las especies herbáceas como a las especies leñosas; en el caso de estas últimas, el efecto del fuego depende de su intensidad y duración, así como también de las características de las especies leñosas involucradas (diámetro, altura, tamaño de copa etc.). Un elemento importante es el grosor de la corteza ya que el daño que el fuego puede generar en la planta dependerá de las características que ésta posea (Bravo et al. 2003).

La información sobre el valor calórico de las maderas puede obtenerse indirectamente a través de metodologías etnobotánicas (Ancibor y Pérez de Micou 2002, Aguirre 2009) que permiten conocer de qué manera las poblaciones locales categorizan a las especies leñosas (como "buenas o malas leñas", o como "ardedoras" o "iniciadoras", por ejemplo). Asimismo, se pueden llevar a cabo ensayos calorimétricos en laboratorio como los realizados por Latzinia (1937) para maderas de la provincia de Tucumán.

\section{Antofagasta de la Sierra: Características ambientales}

La micro-región de Antofagasta de la Sierra (sensu Aschero et al. 2002-04) se encuentra en el ángulo noroeste de la provincia de Catamarca. Está conformada por una cuenca importante que comprende el sistema hídrico de los ríos Calalaste-Toconquis-Punilla/Antofagasta y sus afluentes, dentro de los cuales destacan los ríos Las Pitas y Miriguaca (Figura 1). El área presenta una notable concentración de recursos bióticos y abióticos de diverso tipo para lo que son las características habituales de la Puna Salada de la cual forma parte (Troll 1958), lo que contrasta marcadamente con el ambiente circundante. 
Este espacio puneño se caracteriza ambientalmente por una intensa radiación solar debida a la altitud (3000-4500 m.s.n.m.), una gran amplitud térmica diaria, una marcada estacionalidad con precipitaciones estivales pobres $(0-400 \mathrm{~mm}$ anuales), una baja presión atmosférica y una distribución irregular de nutrientes (Yacobaccio 1994). Desde un punto de vista paleoambiental, el área sufrió condiciones marcadamente áridas y secas entre los 8000 y los 4500 años AP aproximadamente, pasando a un ciclo de mejoramiento climático con mayor humedad ambiental y disponibilidad de agua que se inicia en la última fecha y se extiende hasta los 1600 años AP aproximadamente (Olivera et al. 2006, Tchilinguirian y Olivera 2009).

En la micro-región se pueden distinguir importantes variaciones en el clima, la topografía, la geología y la biomasa (Olivera y Elkin 1994). En este sentido, se puede advertir que la distribución de recursos no es homogénea distinguiéndose áreas de alta concentración de nutrientes (zonas de concentración de nutrientes sensu Yacobaccio 1994) frente a otras de recursos muy dispersos o directamente inexistentes. De este modo, se pueden reconocer en la micro-región tres sectores microambientales con concentración diferencial de recursos (Olivera 1992): Fondo de Cuenca, Sectores Intermedios y Quebradas de Altura.

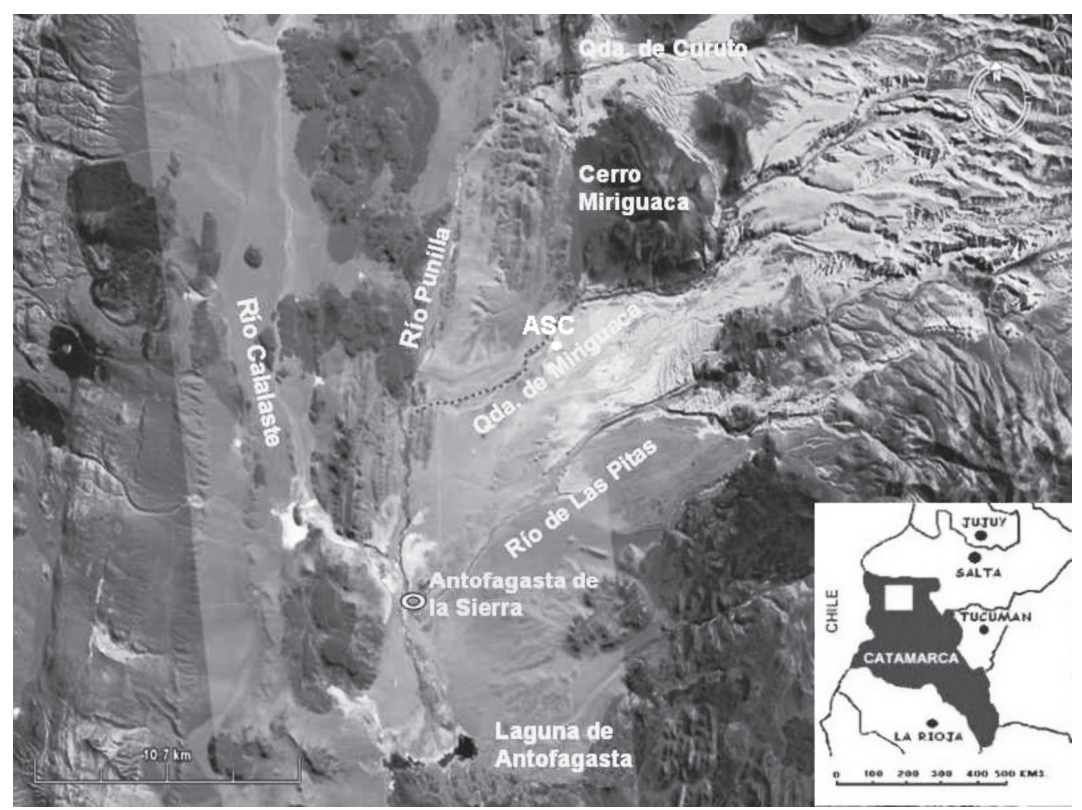

Figura 1: Micro-región de Antofagasta de la Sierra y ubicación del sitio Alero sin Cabeza.

Figure 1: Antofagasta de la Sierra micro-region and Alero Sin Cabeza site location 
Cabe destacar que, si bien la diversidad vegetal de la Puna en general es baja, en la cuenca de Antofagasta de la Sierra es posible diferenciar distintas unidades de vegetación: Vega, Pajonal, Tolar y Campo (Haber 1992). Cada una de éstas puede a su vez dividirse en distintas subunidades caracterizadas por asociaciones florísticas y topografías particulares.

El Fondo de Cuenca comprende el curso inferior del río Punilla y la Laguna de Antofagasta, entre los 3400-3550 m.s.n.m. En ANS los recursos hídricos están focalizados limitándose casi exclusivamente a las quebradas y al fondo de cuenca. Las Vegas constituyen aquí la principal oferta forrajera y se extienden, principalmente, a lo largo del río Punilla/Antofagasta. Cabe destacar que el potencial forrajero de esta subunidad suele incrementarse sustancialmente en función de la presencia de riego artificial (excavación de acequias y/o inundación temporaria de terrenos). Por su parte, las unidades Tolar y Campo constituyen una vegetación de tipo dispersa -arbustiva y herbácea- de limitada importancia forrajera. En general, aparecen en las planicies y laderas cercanas a la vega. De manera global, en este microambiente, la distribución de las especies vegetales es lineal, agrupada o dispersa, desarrollándose especies aptas para forraje, alimento, edificación y tecnología (Haber 1992; Olivera 2006).

Los Sectores Intermedios se ubican entre el Fondo de Cuenca y las Quebradas Altas, entre los 3550 y 3900 m.s.n.m. En cuanto a los recursos vegetales, se ha detectado la disponibilidad de especies forrajeras, leña y otras para fines tecnológicos. En general, dichos recursos se distribuyen también en forma lineal o dispersa (Olivera 2006) en estos sectores. Las unidades vegetacionales identificadas son: Vega (subunidades prepuneña y puneña), Tolar y Campo. El curso inferior y medio de los ríos Las Pitas y Miriguaca, de régimen semipermanente a permanente, concentran en sus márgenes la localización de las vegas.

En el caso de la Vega puneña se destaca una mayor cobertura vegetal que la correspondiente a la subunidad prepuneña $(89.49 \%$ y $67.70 \%$, respectivamente) (Haber 1992). Por otra parte, en las cercanías de estos ríos y con una distribución relacionada a la topografía, se puede advertir el desarrollo de las unidades Tolar, Campo e, incluso, la transición al Pajonal de altura.

Entre los 3900 y los 4600 m.s.n.m. se localizan las Quebradas de Altura, que incluyen los cursos medio y superior de los ríos Las Pitas y Miriguaca, entre otros. Las unidades vegetacionales dominantes son las de Vega (subunidad puneña) y Pajonal. La Vega puneña, desarrollada en los 
fondos de quebrada y en asociación a los cursos de agua, ofrece una alta calidad de forraje pero con una extensión limitada. El Pajonal, por su parte, distribuido en sectores de meseta aledaños a las quebradas, presenta un tipo de vegetación abierta que comprende no solo distintas gramíneas sino también especies arbustivas utilizables como leña.

Tomando en cuenta las unidades de vegetación señaladas, interesa destacar algunas de las especies características asociadas a dichas unidades. En la Vega se han identificado Juncus sp., J. balticus, Triglochin striata y Cortaderia sp. Por su parte, siguiendo con el Tolar, destaca su cobertura vegetal baja. Haber (1992) distingue el predominio de algunas especies y por este motivo dividió a esta unidad en subunidades: Tolar de Atriplex sp., Tolar de Acantholippia salsoloides, Tolar de Senecio subulatus var. salsus y Neosparton ephedroides y Tolar de Parastrephia quadrangularis. Luego, el Campo corresponde a una estepa herbácea y rala con escasos arbustos y no se reconoce el uso actual de esta unidad. Algunas de las especies vegetales identificadas son: Euphorbia sp., Stipa crysophilla, Senecio subulatus Don. var. salsus y Xanthiun spinosum L.. Finalmente, el Pajonal, muestra las siguientes especies características: Festuca crysophilla Phil., Stipa crysophilla, Senecio puchii Phil. y Verbena digitata Phil.

Por último, con respecto a los recursos leñosos, Olivera (2006) considera que la productividad de los mismos en los Sectores Intermedios es media-alta mientras que en el Fondo de Cuenca es baja o escasa.

\section{El sitio Alero sin Cabeza}

El sitio Alero sin Cabeza (ASC) es un reparo rocoso (alero) de importantes dimensiones, comprendiendo unos $12 \mathrm{~m}$ de longitud de protección para el desarrollo de actividades (Figuras 2 y 3 ). Se trata de una base residencial con espacios acondicionados, equipamiento y arte rupestre correspondiente a cazadores-recolectores transicionales. La presencia de artefactos, ecofactos y estructuras de diversa índole señala la ocurrencia de múltiples actividades. 


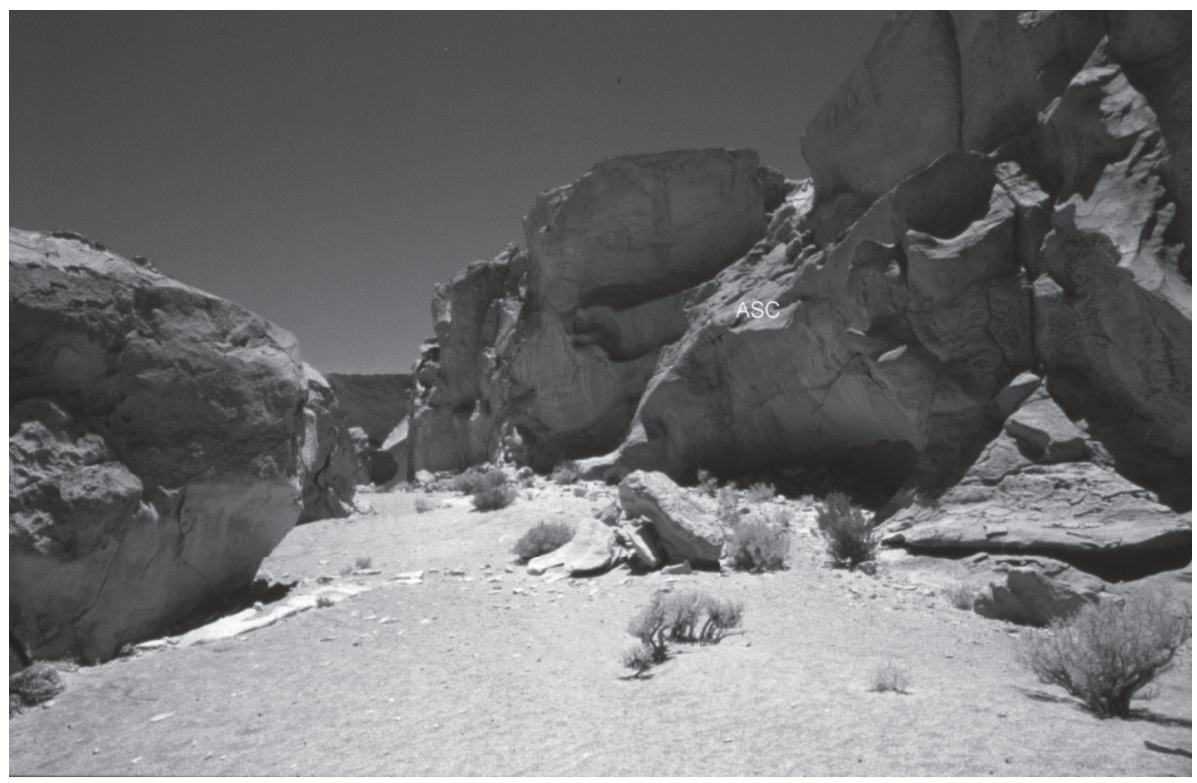

Figura 2: El sitio Alero sin Cabeza.

Figure 2: The site Alero sin Cabeza.

Los espacios acondicionados se definen por estructuras de piedra contra la pared del alero. Asimismo, artefactos y ecofactos se presentan en el "sector exterior estructuras" donde se habrían desarrollado distintas actividades cotidianas. El equipamiento se asume por la presencia de artefactos de molienda en el mismo sector exterior. El arte rupestre consiste en la presencia de tres camélidos grabados, dos de grandes dimensiones y un tercero pequeño. Cabe destacar que, de acuerdo a sus características formales, los dos camélidos grandes se corresponden con la modalidad estilística Río Punilla definida por Aschero (2006), que fue fechada relativamente por este autor entre los 3500 y los 2500 años AP.

Los fechados radiocarbónicos obtenidos hasta el momento en ASC sobre muestras de carbón son los siguientes: en el sector externo a las estructuras se obtuvieron dos dataciones de 3610 70 años AP (LP 1796) (Sondeo Reparo bajo Roca) y $3470 \pm 60$ años AP (LP 1835), mientras que en el interior de una de las estructuras el fechado resultó en $3390 \pm 70$ años AP (LP1846). Se debe señalar que estos fechados son plenamente concordantes con las características tecno-tipológicas de los conjuntos líticos tallados y de molienda recuperados, ya que estos conjuntos artefactuales pueden vincularse con sitios de similar cronología, como los de la quebrada próxima de Las Pitas (Babot 2004; Hocsman 2006). 
Sitio Alero Sin Cabeza

Planta General

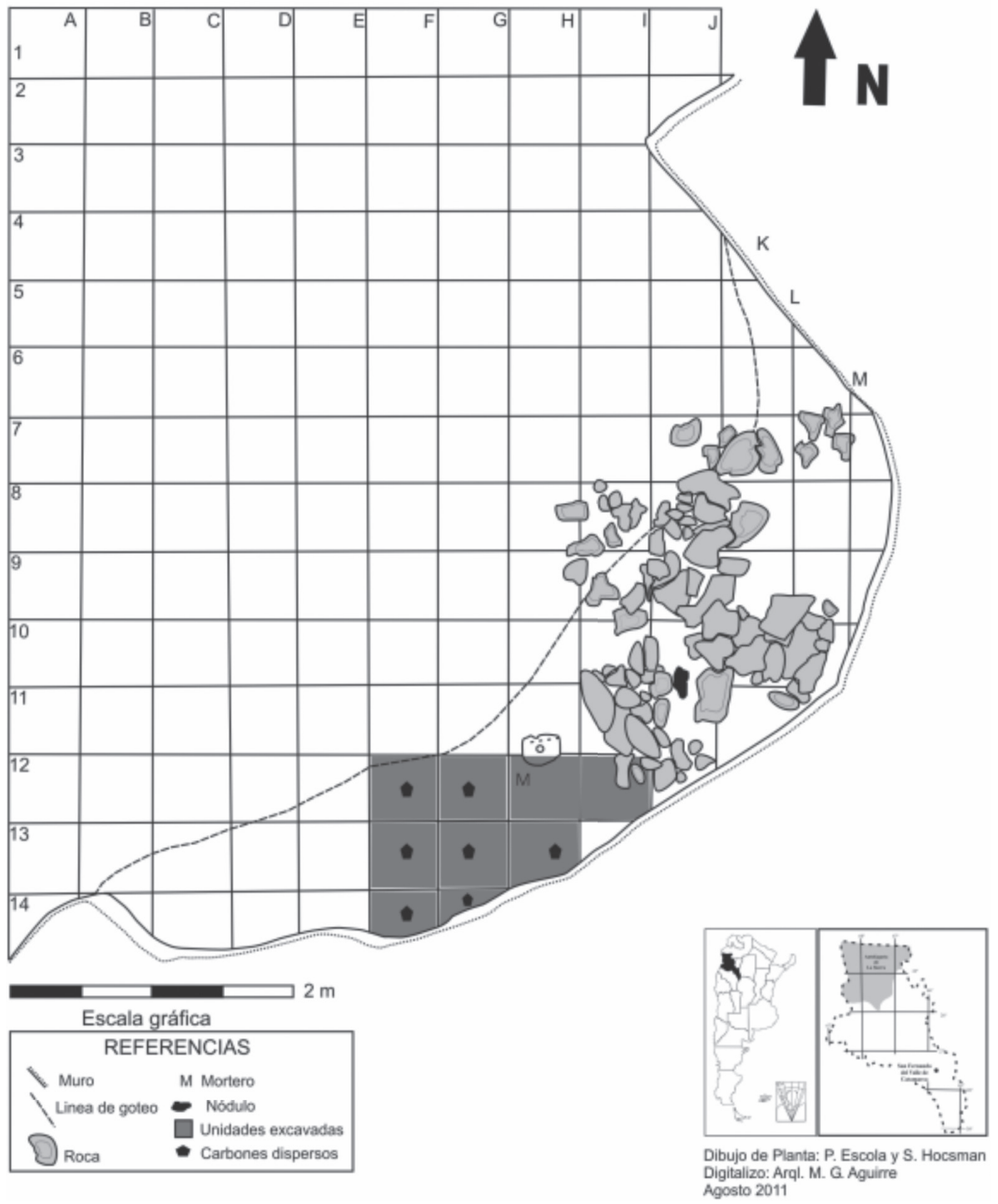

Figura 3: Planta general del sitio Alero sin Cabeza y unidades excavadas.

Figure 3: General map site of Alero sin Cabeza and excavated units.

Por otro lado, en este sitio se presenta también una ocupación agropastoril, restringida hasta el momento al fondo del alero, y que estaría reclamando (involucrando desarme) parte de las estructuras anteriormente citadas. Al respecto, en el interior de una de las estructuras se ha fechado un endocarpo de algarrobo por AMS obteniéndose una datación de $1745 \pm 40$ 
años AP (Ua-33240, $\delta 13 \mathrm{C}-26,3 \%)$. Las evidencias de esta ocupación agropastoril no serán tratadas en este trabajo.

Las ocupaciones de cazadores-recolectores transicionales en el sitio Alero sin Cabeza se desarrollaron bajo condiciones de mayor humedad plenamente instaladas, lo que permite contextualizar la disponibilidad de recursos leñosos en el área.

Los fechados radiocarbónicos se enmarcan dentro del proceso transicional local de un modo de vida cazador-recolector a otro agro-pastoril, identificado hacia los 3500 años AP (Hocsman 2006; Aschero y Hocsman 2011) y con cambios reconocibles desde el 5000 años AP que muestran una progresiva reducción de la movilidad residencial en el marco de un proceso de sedentarización (Aschero y Hocsman 2011).

En estos momentos, siguiendo a Aschero et al. (1993-94), se estaría en presencia de una movilidad pautada, con retorno a lugares previstos, en el marco de un sistema semi-sedentario o bien de recorridos/ circuitos estacionales bien demarcados. Cabe destacar que el hecho de un grado creciente de fijación de los sitios al paisaje a escala micro no debe llevar obligatoriamente a que la circulación regional/macroregional disminuya o deje de funcionar. Al respecto, la información disponible en el área parecería sustentar, justamente, una micromovilidad reducida y una macromovilidad en pleno funcionamiento a fines del Holoceno Medio y durante el Holoceno Tardío (Hocsman 2002, 2006), lo que debe haber tenido consecuencias sobre la gestión de recursos leñosos.

\section{Metodología de trabajo}

El estudio realizado incluyó dos fases de trabajo: campo y laboratorio. Durante los trabajos de campo, en primera instancia, se describió la vegetación que actualmente rodea al alero. Las especies identificadas fueron Añahua (Adesmia horrida Gillies ex Hook. \& Arn.), Rica-Rica (Acantholippia deserticola (Phil.) Moldenke) y Tramontana (Ephedra breana Phil.), de aparición frecuente entre los farallones y bloques derrumbados de ignimbritas. Por su parte, en los sectores de acceso al sitio se identificó Tolilla (Fabiana punensis S.C. Arroyo), en mayor proporción, y Acerillo (Lycium chañar Phil.), en menor medida.

En segunda instancia, en el campo se procedió a recuperar la muestra antracológica a partir de una excavación estratigráfica por capas naturales para un total de nueve unidades de excavación (Figura 3). De este modo, se 
aplicó la recolección directa de los carbones durante la excavación del alero y la recuperación en zaranda a través de tamizados empleando mallas de distintos tamaños (entre 5 y $2 \mathrm{~mm}$ ). Se debe destacar que en la excavación se identificaron áreas de dispersión carbonosa y de acumulación de carbones pero no estructuras de combustión concretas o fogones.

Las muestras antracológicas se recuperaron considerando las dos formas fundamentales en las que se puede encontrar el carbón: disperso o concentrado. Al respecto, en general se considera que el carbón disperso es el que se presenta esparcido por todo el nivel de ocupación e informa principalmente sobre condiciones paleoambientales; por su parte, el carbón concentrado es aquél que procede, por ejemplo, de estructuras de combustión e informa principalmente sobre aspectos paleoeconómicos (Chabal 1992). De esto se desprende la concepción de un origen eminentemente natural de los carbones dispersos (por ejemplo, quemas naturales); sin embargo, en el caso aquí abordado, se trata de un reparo rocoso que define un lugar protegido de los elementos, a bastante resguardo del exterior, por lo que es muy posible que la actividad humana sea el principal agente de formación. Por ejemplo, bajo la forma de limpiezas de fogón que generaron áreas de dispersión carbonosa y de pisoteo/pateo/limpiezas que movilizaron carbones dispersos por todo el nivel. Por ende, podemos pensar que los carbones responden a actividades humanas, siendo los concentrados y los dispersos parte de los mismos procesos de formación y transformación, con la diferencia de que los dispersos denotarían instancias previas de utilización. De manera secundaria, no se puede dejar de tener en cuenta la acción de la lluvia o el viento coadyuvando en la dispersión mencionada.

El principio sobre el que se basan los estudios antracológicos es la variación interna del leño según cada especie, aún cuando el material haya sido expuesto al fuego. En este sentido, la disposición y características de las células que componen el leño permiten la identificación taxonómica del mismo (Fahn 1974, Piqué i Huerta 1999, Castro 2002).

Los carbones vegetales arqueológicos que se analizan en este trabajo fueron estudiados en laboratorio a fin de reconocer los taxones que integran la muestra. En esta etapa, los estudios previos realizados en el área (Rodríguez 1999, 2000, 2004a y b; Aguirre 2007) y la colección de carbones actuales generada a partir de quemas experimentales en campo y laboratorio (Aguirre 2012) fueron esenciales ya que permitieron realizar la tarea de identificación taxonómica. También se consultó material bibliográfico del área de estudio (Rodríguez 2000, 2004a y b, Aguirre 2007). 
Cada carbón arqueológico se fracturó según los planos: a) transversal, en el que se distinguen caracteres fundamentales tales como las tráqueas, vasos de conducción y anillos anuales de crecimiento (Pique i Huerta y Pique i Huerta 1991), y b) longitudinal tangencial y longitudinal radial, donde se observan las tráqueas longitudinalmente, las perforaciones y otros elementos de la arquitectura interna de la madera, tales como traqueidas, fibras, y radios (Pique i Huerta y Pique i Huerta 1991). Asimismo, se comparó la estructura anatómica de los individuos arqueológicos con la de los carbones de la colección de referencia. Los fragmentos se analizaron utilizando microscopio óptico adaptado con iluminación externa a 10, 40 y $100 \mathrm{X}$. Se tomaron fotografías con Microscopio Electrónico de Barrido (Philips XL 30) del servicio de microscopia del Museo Argentino de Ciencias Naturales Bernardino Rivadavia.

El conjunto de carbones que procede del sitio es heterogéneo ya que difieren en cuanto al tamaño de los fragmentos: grandes, medianos, pequeños, astillas (trozos de forma irregular de menos de $1 \mathrm{~mm}$ ), número y estado de preservación. Considerando la procedencia del material, según su recuperación en la excavación, fue posible discriminar entre los carbones que procedían del sedimento de los niveles arqueológicos y aquellos procedentes de espacios circunscriptos (Figura 4).

En el laboratorio se procedió a registrar para cada muestra los siguientes datos: número, peso y volumen total de carbones recuperados, y número, peso y volumen real analizado. Para obtener una muestra representativa de los taxones utilizados en el sitio, los carbones se seleccionaron tomando como primer criterio el tamańo del ejemplar; aquellos que no tuvieran un tamaño y resistencia para realizar cortes frescos no fueron considerados. Del total de la muestra, se trabajó solo con aquellos fragmentos $\geq 5 \mathrm{~mm}$. Para evitar elegir solo los fragmentos grandes, cada muestra a ser analizada se subdividió en grupos de carbones de tamaños similares y se tomaron ejemplares de cada subgrupo. En esta etapa del muestreo se aplicó la curva de riqueza específica que consiste en registrar en una grilla cada taxón cuando aparece por primera vez (Piqué i Huerta 1999). 


\section{Alero sin Cabeza}

\section{Excavación Exterior Estructura}

Nivel 1
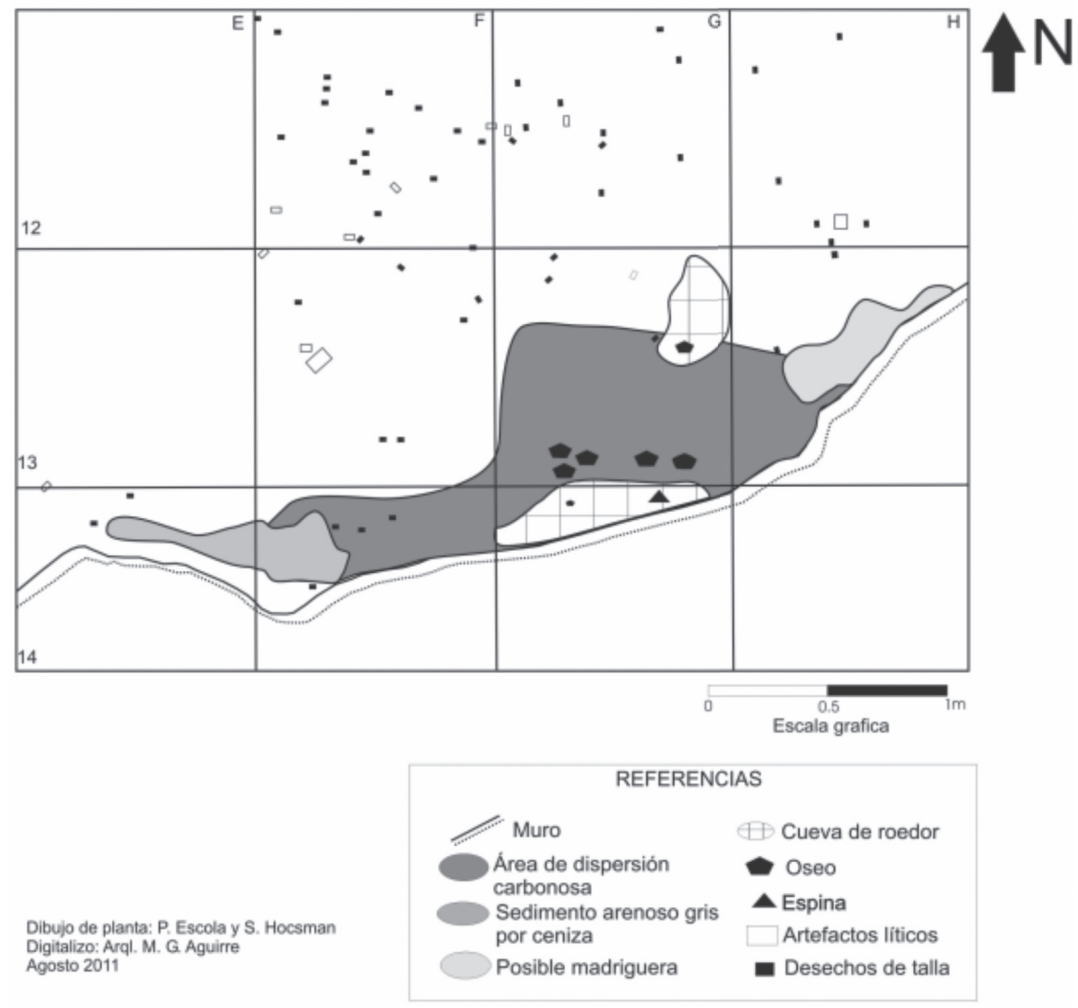

Figura 4: Planta de excavación del Nivel. Localización de sectores de carbones concentrados.

Figure 4: Level 1excavation map site. Location of concentrated charcoal sectors.

\section{Resultados}

Siguiendo la metodología señalada, se analizó un total de 496 fragmentos recuperados en estratigrafía en el área excavada exterior a las estructuras, correspondiendo a carbones dispersos y concentrados.

En líneas generales, en el sitio Alero sin Cabeza hemos identificado ejemplares de los géneros Adesmia sp., Acantholippia sp., Fabiana sp., Parastrephia sp., Aff. Parastrephia sp., además a Aff. Adesmia sp., Aff. Fabiana sp. y especímenes de las siguientes especies: Acantholippia deserticola, Adesmia horrida, Atriplex imbricata, Chuquiraga atacamensis Fabiana 
bryoides, Fabiana punensis, Parastrephia lucida, Parastrephia quadrangularis y Sysimbrium phillipianum. Cabe destacar que los 16 taxa corresponden a ejemplares de la flora local (Figura 5 a y b). La descripción de la anatomía de los mismos se desarrolla en las Tablas 1 y 2. Por su parte, la cuantificación de la muestra de carbón disperso y carbón concentrado brindó los resultados que se presentan en las Tablas 3, 4 y 5.
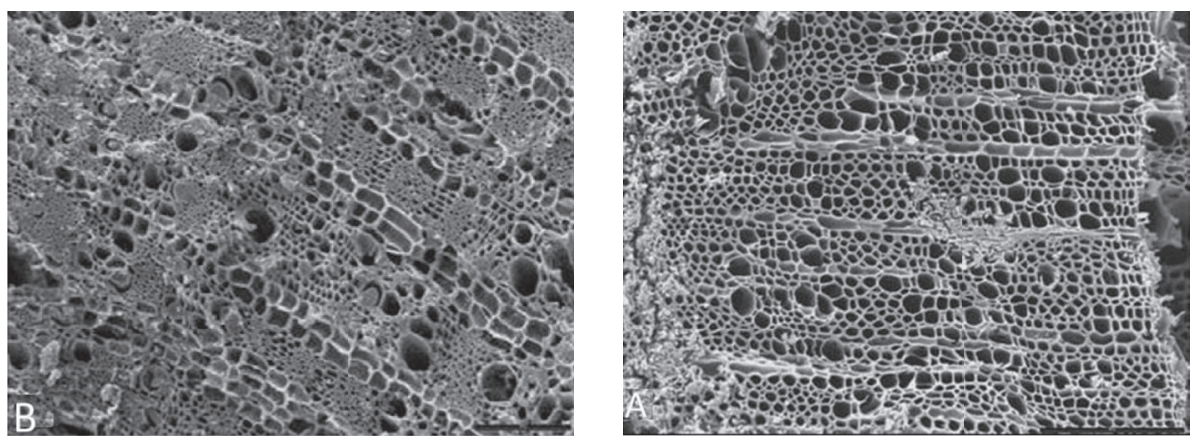

Figura 5: a) Acantholippia deserticola (Phil.) Moldenke (Rica-Rica). Ejemplar arqueológico. Corte Transversal de tallo, 300x. Barra $100 \mu \mathrm{m}$. B-Adesmia horrida Gillies ex Hook. \& Arn. (Añahua). Ejemplar arqueológico. Corte Transversal de tallo, 200x. Barra 100 um.; b) Adesmia horrida Gillies ex Hook. \& Arn. (Añahua).

Ejemplar arqueológico. Corte Transversal de tallo, 200x. Barra $100 \mu \mathrm{m}$.

Figure 5: a) Acantholippia deserticola (Phil.) Moldenke (Rica-Rica). Archaeological charcoal. Woody stem. Cross section, 300 x. Bar 100 um. B-Adesmia horrida ex Hook. \& Arn. (Añahua). Archaeological charcoal. Woody stem. Cross section, 200 x. Bar 100 um.; b) Adesmia horrida ex Hook. \& Arn. (Añahua). Archaeological charcoal. Woody stem. Cross section, $200 \times$. Bar $100 \mu \mathrm{m}$. 


\begin{tabular}{|c|c|c|}
\hline Taxón & Corte transversal (CTr) & $\begin{array}{l}\text { Corte longitudinal tangencial } \\
(\mathrm{CT}) \mathrm{y} \text { radial }(\mathrm{CR})\end{array}$ \\
\hline $\begin{array}{l}\text { Acantholippia } \\
\text { deserticola } \\
\text { (Figura 5a) }\end{array}$ & $\begin{array}{l}\text { Anillos de crecimiento marcados. } \\
\text { Porosidad subcircular. Vasos } \\
\text { de contorno angular y paredes } \\
\text { delgadas dispuestos en racimos, } \\
\text { series largas, cortas y tangenciales. } \\
\text { Radios en su mayoría uniseriados, } \\
\text { parénquima axial paratraqueal que } \\
\text { rodea a los vasos. Fibras de paredes } \\
\text { delgadas y células parenquimáticas } \\
\text { con puntuaciones alternas. }\end{array}$ & $\begin{array}{l}\text { Los elementos vasculares } \\
\text { son relativamente largos y se } \\
\text { comunican entre sí mediante } \\
\text { puntuaciones areoladas y placas } \\
\text { de perforación simples y oblicuas. } \\
\text { El sistema radial es heterogéneo } \\
\text { con radios uni y pluriseriados (2-4 } \\
\text { células). Radios heterocelulares. } \\
\text { Crecimiento secundario helicoidal } \\
\text { entre los elementos vasales. }\end{array}$ \\
\hline $\begin{array}{l}\text { Adesmia } \\
\text { horrida } \\
\text { (Figura 5b) }\end{array}$ & $\begin{array}{l}\text { Anillos de crecimiento marcados. } \\
\text { Porosidad difusa en la raíz y } \\
\text { subcircular en el tallo. Vasos } \\
\text { de paredes delgadas y contorno } \\
\text { circular; en el tallo se presentan } \\
\text { solitarios, en series cortas, } \\
\text { tangenciales y en disposición } \\
\text { dendrítica En la raíz se disponen } \\
\text { solitarios y en series tangenciales. } \\
\text { Parénquima axial paratraqueal } \\
\text { en bandas entre los paquetes de } \\
\text { fibras y vasos. Tanto en el tallo } \\
\text { como en la raíz se observan } \\
\text { paquetes de fibras intercalados } \\
\text { con grupos de vasos. Fibras de } \\
\text { paredes engrosadas y células } \\
\text { parenquimáticas de paredes } \\
\text { delgadas. Puntuaciones alternas } \\
\text { en las células parenquimáticas. } \\
\text { Se observa también la S3 (pared } \\
\text { terciaria) en hélice en el interior de } \\
\text { algunos vasos. }\end{array}$ & $\begin{array}{l}\text { Los elementos vasculares son } \\
\text { cortos. Radios heterocelulares. }\end{array}$ \\
\hline $\begin{array}{l}\text { Atriplex } \\
\text { imbricata }\end{array}$ & $\begin{array}{l}\text { Crecimiento anómalo de floema } \\
\text { que alterna con anillos del xilema. }\end{array}$ & Punteaduras simples. \\
\hline $\begin{array}{l}\text { Chuquiraga } \\
\text { atacamensis }\end{array}$ & $\begin{array}{l}\text { Vasos de contorno subredondeado, } \\
\text { formando series cortas y largas. } \\
\text { Radios uni a multiseriados. } \\
\text { Parénquima axial paratraqueal. }\end{array}$ & $\begin{array}{l}\text { Los elementos vasculares tienen } \\
\text { una longitud mediana. Radios } \\
\text { heterocelulares. }\end{array}$ \\
\hline
\end{tabular}

Tabla 1: Alero sin Cabeza. Descripción anatómica de los ejemplares identificados a nivel especifico.

Table 1: Alero sin Cabeza. Anatomical description of the specimens identified to specific level. 


\begin{tabular}{|c|c|c|}
\hline Taxón & Corte Transversal (Ctr) & $\begin{array}{l}\text { Corte Longitudinal Tangencial } \\
\text { (CT) y Radial (CR) }\end{array}$ \\
\hline $\begin{array}{l}\text { Fabiana } \\
\text { bryoides }\end{array}$ & $\begin{array}{l}\text { Anillos de crecimiento marcados. } \\
\text { Porosidad subcircular. Vasos } \\
\text { de contorno angular y paredes } \\
\text { delgadas. Solitarios en series } \\
\text { cortas, radiales y tangenciales. } \\
\text { Parenquima axial paratraqueal y } \\
\text { difuso apotraqueal. }\end{array}$ & $\begin{array}{l}\text { Elementos vasculares de tamańo } \\
\text { variable, placas de perforación } \\
\text { simple, oblicuas en algunos casos. } \\
\text { Las fibrotraqueidas presentan } \\
\text { paredes delgadas. Radios } \\
\text { heterocelulares. Sistema radial } \\
\text { heterogéneo. Radios biseriados y } \\
\text { uniseriados. }\end{array}$ \\
\hline $\begin{array}{l}\text { Fabiana } \\
\text { punensis }\end{array}$ & $\begin{array}{l}\text { Porosidad subcircular. Vasos de } \\
\text { contornos angulares y paredes } \\
\text { delgadas. Se disponen solitarios, } \\
\text { en series radiales cortas y algunos } \\
\text { en series tangenciales. Fibras con } \\
\text { puntuaciones simples. Parenquima } \\
\text { paratraqueal. }\end{array}$ & $\begin{array}{l}\text { Los elementos vasculares tienen } \\
\text { tamańos variables. Se comunican } \\
\text { por placas de perforación } \\
\text { simples u oblicuas. Sistema } \\
\text { radia homogéneo. Radios } \\
\text { heterocelulares formado por } \\
\text { células cúbicas o procumbentes } \\
\end{array}$ \\
\hline $\begin{array}{l}\text { Parastrephia } \\
\text { quadrangularis }\end{array}$ & $\begin{array}{l}\text { Porosidad difusa. Vasos de } \\
\text { contorno circular y de diámetro } \\
\text { reducido. Se presentan solitarios, } \\
\text { en series cortas y largas radiales. } \\
\text { Abundantes fibras de paredes } \\
\text { engrosadas. Parenquima axial } \\
\text { paratraqueal difuso y escaso. }\end{array}$ & $\begin{array}{l}\text { Elementos vasculares cortos } \\
\text { conectados por punteaduras } \\
\text { alternas simples. Fibras con } \\
\text { punteaduras escasas. Rayos } \\
\text { multiseriados. Sistema } \\
\text { radial heterogéneo. Radios } \\
\text { heterocelulares con células } \\
\text { verticales y procumbentes. } \\
\end{array}$ \\
\hline $\begin{array}{l}\text { Parastrephia } \\
\text { lucida }\end{array}$ & $\begin{array}{l}\text { Las fibras son relativamente } \\
\text { abundantes, de paredes } \\
\text { engrosadas, los vasos se disponen } \\
\text { arreglados alrededor de las } \\
\text { fibras. Los vasos tienen contorno } \\
\text { circular, se disponen solitarios o en } \\
\text { grupos. Parenquima axial escaso y } \\
\text { paratraqueal difuso. }\end{array}$ & $\begin{array}{l}\text { Los elementos vasculares son } \\
\text { relativamente cortos, se observan } \\
\text { placas de perforación simples y } \\
\text { oblicuas, punteaduras areoladas, } \\
\text { radios uniseriados y pluriseriados. }\end{array}$ \\
\hline $\begin{array}{l}\text { Sysimbrium } \\
\text { phillipianum }\end{array}$ & $\begin{array}{l}\text { Porosidad difusa con tendencia a } \\
\text { ser subcircular. Vasos de contorno } \\
\text { circular, solitarios, en series largas } \\
\text { y cortas. Fibras abundantes. } \\
\text { Anillos de crecimiento marcados }\end{array}$ & $\begin{array}{l}\text { Los elementos vasculares tienen } \\
\text { una longitud mediana, se } \\
\text { comunican por punteaduras } \\
\text { alternas areoladas y simples. Se } \\
\text { observan placas de perforaciones } \\
\text { simples y oblicuas. Radios } \\
\text { heterocelulares, con células } \\
\text { verticales y cúbicas. Sistema radial } \\
\text { homogéneo. }\end{array}$ \\
\hline
\end{tabular}

Tabla 2: Alero sin Cabeza. Descripción anatómica de los ejemplares identificados a nivel especifico.

Table 2: Alero sin Cabeza. Anatomical description of the specimens identified to specific level. 


\begin{tabular}{|l|l|l|l|l|l|l|l|}
\hline Nivel & $\begin{array}{l}\text { No total } \\
\text { fragmentos }\end{array}$ & $\begin{array}{l}\text { Peso } \\
\text { total } \\
(\mathrm{g})\end{array}$ & $\begin{array}{l}\text { Volumen } \\
\text { total }(\mathrm{ml})\end{array}$ & $\begin{array}{l}\text { No } \\
\text { fragmentos } \\
+5 \mathrm{~mm}\end{array}$ & $\begin{array}{l}\text { No } \\
\text { fragmentos } \\
\text { analizados } \\
\text { (sobre total } \\
\text { de }+5 \mathrm{~mm})\end{array}$ & $\begin{array}{l}\text { Peso } \\
\text { analizado } \\
(\mathrm{g})\end{array}$ & $\begin{array}{l}\text { Volumen } \\
\text { analizado } \\
(\mathrm{ml})\end{array}$ \\
\hline 0 & 2 & 0 & 0 & 2 & 2 & 0 & 0 \\
\hline 1 & 189 & 4,26 & 22,5 & 129 & 56 & 2,25 & 10 \\
\hline 2 & 286 & 12,77 & 58 & 267 & 102 & 4,97 & 19,5 \\
\hline
\end{tabular}

Tabla 3: Alero Sin Cabeza. Cuantificación de los carbones dispersos recuperados en el exterior de estructuras

Table 3: Alero Sin Cabeza. Quantification of the recovered charcoals scattered outward structures

\begin{tabular}{|l|l|l|l|l|l|l|l|}
\hline Nivel 1 & $\begin{array}{l}\text { No total } \\
\text { fragmentos }\end{array}$ & $\begin{array}{l}\text { Peso } \\
\text { total } \\
(\mathbf{g})\end{array}$ & $\begin{array}{l}\text { Volumen } \\
\text { total } \\
(\mathbf{m l})\end{array}$ & $\begin{array}{l}\mathbf{N o} \\
\text { fragmentos } \\
\mathbf{+ 5 m m}\end{array}$ & $\begin{array}{l}\mathbf{N o} \\
\text { fragmentos } \\
\text { analizados } \\
(\mathbf{s o b r e ~ t o t a l} \\
\mathbf{d e}+5 \text { mm })\end{array}$ & $\begin{array}{l}\text { Peso } \\
\text { analizado } \\
(\mathbf{g})\end{array}$ & $\begin{array}{l}\text { Volumen } \\
\text { analizado } \\
(\mathbf{m l})\end{array}$ \\
\hline $\begin{array}{l}\text { Área } \\
\text { carbonosa }\end{array}$ & 131 & 4,26 & 17,5 & 81 & 41 & 2,62 & 10 \\
\hline $\begin{array}{l}\text { Área de } \\
\text { dispersión } \\
\text { carbonosa }\end{array}$ & 122 & 1,57 & 7,5 & 97 & 20 & 0,45 & 2 \\
\hline $\begin{array}{l}\text { Núcleo } \\
\text { área } \\
\text { carbonosa }\end{array}$ & 20 & 1,15 & 5 & 18 & 9 & 0,69 & 2 \\
\hline $\begin{array}{l}\text { Muestra } \\
\text { de carbón }\end{array}$ & 696 & 22,75 & 100 & 537 & 266 & 11,81 & 57 \\
\hline
\end{tabular}

Tabla 4: Alero sin Cabeza. Cuantificación de carbones concentrados

Table 4: Alero sin Cabeza. Quantification of concentrated charcoal

Ahora bien, del total de taxa registrados durante los análisis antracológicos, 10 se identificaron en la muestra de carbones dispersos (Tabla 5, Figura 6) y 14 de ellos están representados en la muestra de carbones concentrados (Tabla 5, Figura 7), lo que hace relevante distinguir entre ambos tipos de carbones y no privilegiar una sobre otra.

Las frecuencias de carbones revelan una preponderancia de Adesmia sp., tanto en carbones dispersos $(73,75 \%)$ como concentrados $(52,08 \%)$, siguiéndoles en orden de importancia Acantoliphia sp. (16,25\%) y Fabiana sp. $(6,87 \%)$ en el primer caso; y Fabiana sp. $(22,61 \%)$ y Acantholippia sp. $(14,88 \%)$ en el segundo caso; es decir, se presentan invertidos en frecuencia dichos recursos combustibles secundarios (Figuras 6 y 7 ). 


\begin{tabular}{|l|l|l|}
\hline \multirow{2}{*}{ Taxa } & Carbones \\
\cline { 2 - 3 } & Dispersos & Concentrados \\
\hline Acantholippia sp. & 26 & 1 \\
\hline Acantholippia deserticola & - & 49 \\
\hline Adesmia sp. & 106 & 88 \\
\hline Adesmia horrida & 9 & 87 \\
\hline Aff. Adesmia & 3 & - \\
\hline Atriplex imbricata & - & 10 \\
\hline Chuquiraga atacamensis & - & 1 \\
\hline Fabiana sp. & 6 & 17 \\
\hline Fabiana bryoides & 3 & 30 \\
\hline Fabiana punensis & 1 & 29 \\
\hline Aff. Fabiana & 1 & - \\
\hline Parastrephia sp. & 4 & 4 \\
\hline Parastrephia quadrangularis & - & 2 \\
\hline Parastrephia lucida & 1 & 16 \\
\hline Aff. Parastrephia sp. & - & 1 \\
\hline Sysimbrium phillipianum & - & 1 \\
\hline Total & $\mathbf{1 6 0}$ & $\mathbf{3 3 6}$ \\
\hline
\end{tabular}

Tabla 5: Alero sin Cabeza. Cantidades de carbones dispersos y concentrados por taxa. Table 5: Alero sin Cabeza. Quantities of disperse and concentrated charcoal per taxa.

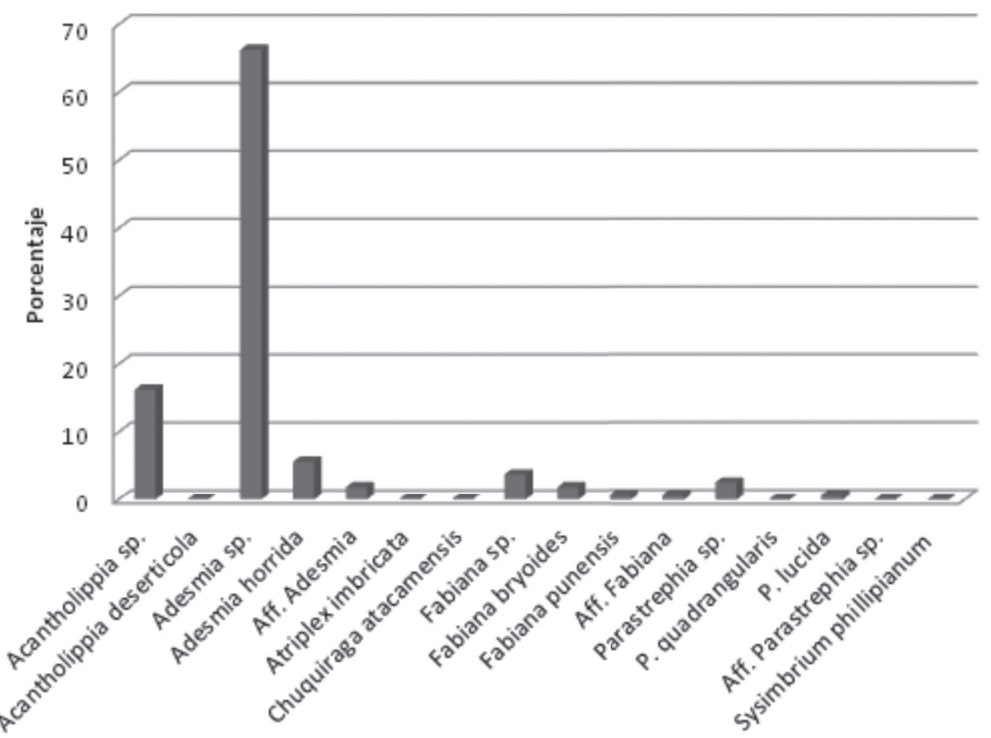

Figura 6: Alero sin Cabeza. Taxa identificados en la muestra de carbones dispersos. Figure 6: Alero sin Cabeza. Taxa identified in the sample of disperse charcoal. 
Entonces, entre las especies leñosas utilizadas podemos destacar el género Adesmia sp., y concretamente, la especie $A$. horrida, como los taxa mejor representados. Se puede señalar que para el área de Antofagasta de la Sierra actualmente se han identificado: A erinacea Phil., A. horrida, A. minor (Hook. \& Arn.) Burkart y A. trijuga Gill ex. Hook. \& Arn. (Cuello 2006). Cuello (2006) señala que $A$. horrida es abundante en el Campo y en el Tolar, al igual que $A$. trijuga, lo es en el Tolar. Asimismo, en la unidad vegetacional del Pajonal se ha identificado también A. caespitosa Phil. (Olivera 2006).

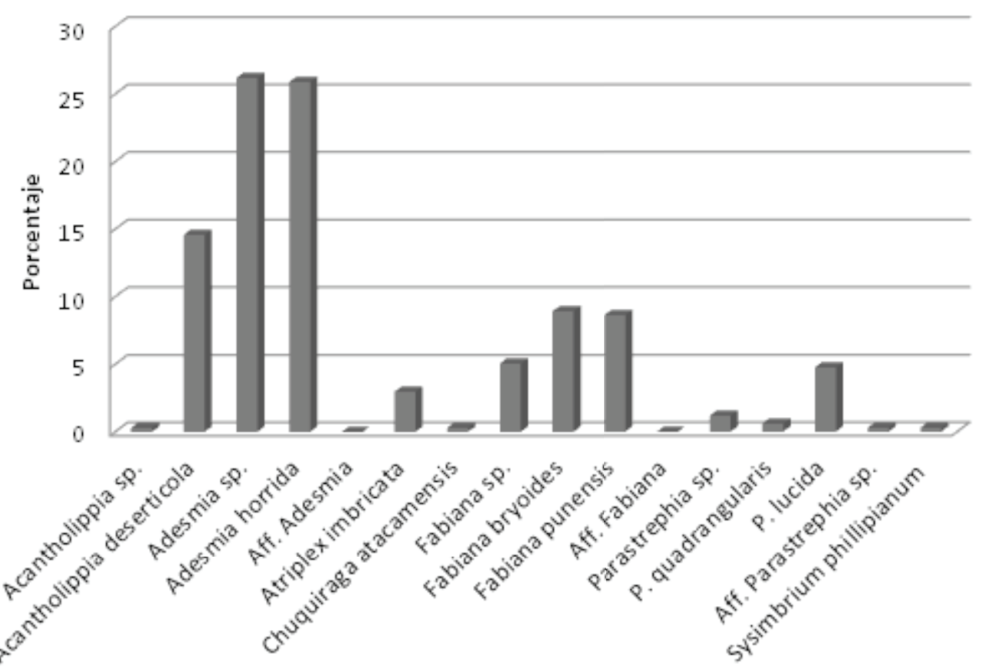

Figura 7: Alero sin Cabeza. Taxa identificados en la muestra de carbones concentrados.

Figure 7: Alero sin Cabeza. Taxa identified in the sample of concentrated charcoal.

Diversas especies del género Adesmia sp. son consideradas buen combustible, incluyendo las nombradas (Villagrán y Castro 2004). En ANS se menciona la presencia de A. echinus C. Presl como combustible y con fines medicinales (Pérez 2006); de Adesmia sp. como leña, aunque no es considerada uno de los mejores combustibles (Joly et al. 2009, Aguirre 2009); en otros casos se ha especificado que $A$. horrida es considerada una leña de invierno (Aguirre 2009). En cuanto a otro de los recursos leñosos representados en el sitio, se puede señalar que $A$. desertícola ha sido identificada, según datos etnobotánicos, como una leña de verano mientras que Parastrephia lucida y Parastrephia quadrangularis son consideradas leñas de invierno (Aguirre 2009). 
En la Tabla 6 se sintetizan los diferentes usos actuales en ANS, Susques y Norte de Chile de las principales especies identificadas. En el caso de ANS se incluye su pertenencia a las unidades vegetacionales. En general, se observa el uso primordial de las mismas como combustible.

No hay registros etnobotánicos actuales de uso de Atriplex imbricata y de Sysimbrium phillipianum como leña, ni en ANS ni en Susques (Aguirre 2009; Joly et al. 2009).

\section{Discusión}

Como se mencionó previamente, la dispersión de los carbones en los niveles arqueológicos es en general una consecuencia de procesos de limpieza y remoción de los hogares domésticos o debido a agentes naturales como la lluvia o el viento que esparcen los restos (Badal et al. 2003). En el sitio, los carbones dispersos representan un total de 477 fragmentos que mayoritariamente miden más de $5 \mathrm{~mm}$ (Tabla 3 ) y se distribuyen en sectores próximos a las áreas de concentración de carbones. Por otra parte, el carbón concentrado es el que aparece en estructuras de combustión como hogares $\mathrm{u}$ hornos o como acumulaciones en agujeros de poste (Kahn y Coil 2006) o en estructuras de tipo funerario (Grau 1992), indicando en estos casos la última quema que se realizó en una determinada estructura (Chabal 1992). En Alero Sin Cabeza se debe señalar que se identificaron, en el exterior de las estructuras, áreas de dispersión carbonosa y de acumulación de carbones pero no estructuras de combustión concretas (fogones), considerando la tipología general propuesta por March y Wünsch (2003). Las acumulaciones de restos situadas en sectores contiguos al muro que delimita el alero, representados por un total de 969 fragmentos (Tabla 4), la diversidad taxonómica observada y la sobre-representación del género Adesmia y la especie $A$. horrida serían coincidentes con el origen de estas concentraciones de carbón que se pueden interpretar inicialmente como acumulaciones intencionales producto de limpiezas del interior de las estructuras. Destaca también el uso reiterado de un mismo sector del sitio para depositar estos residuos de combustión. Lo dicho no implica que no se pudieron haber desarrollado otras actividades en el espacio exterior a las estructuras, más allá del descarte. Esto podría indicar una ocupación al menos recurrente de Alero Sin Cabeza por lo que las tareas de limpieza del hogar/hogares serían necesarias. 


\begin{tabular}{|c|c|c|c|}
\hline Taxón & $\begin{array}{l}\text { Unidad } \\
\text { Vegetacional } \\
\text { en ANS } \\
\end{array}$ & Usos & Referencia \\
\hline $\begin{array}{l}\text { Acantholippia desertícola } \\
\text { ("Rica-Rica") }\end{array}$ & Tolar y Campo & Leña & $\begin{array}{l}\text { Villagrán y Castro } \\
\text { 2004; Aguirre } 2009\end{array}$ \\
\hline Acantholippia punensis & - & $\begin{array}{l}\text { Leńa, iniciadora } \\
\text { de combustiones }\end{array}$ & $\begin{array}{l}\text { Jofré 2007; Joly et al. } \\
2009\end{array}$ \\
\hline $\begin{array}{l}\text { Fabiana bryoides } \\
\text { ("Pata de Perdiz" o } \\
\text { "Leña de Perdiz") }\end{array}$ & Vega y Pajonal & Leña, sahumar & $\begin{array}{l}\text { Villagrán y Castro } \\
\text { 2004; Pérez 2006; Joly } \\
\text { et al. } 2009\end{array}$ \\
\hline $\begin{array}{l}\text { Parastrephia lucida } \\
\text { ("Tola de río") }\end{array}$ & Tolar & Leña & $\begin{array}{l}\text { Villagrán y Castro } \\
\text { 2004; Aguirre } 2009\end{array}$ \\
\hline $\begin{array}{l}\text { Parastrephia } \\
\text { quadrangularis } \\
\text { ("Chacha") }\end{array}$ & Tolar y Campo & Leña, sahumar & $\begin{array}{l}\text { Villagrán et al. } 1998 ; \\
\text { Villagrán y Castro } \\
\text { 2004; Aguirre } 2009\end{array}$ \\
\hline $\begin{array}{l}\text { Chuquiraga atacamensis } \\
\text { ("Monte de suri") }\end{array}$ & Tolar y Campo & Leña (raíz) & Villagrán y Castro 2004 \\
\hline Atriplex imbricata & Tolar y Campo & Leña & Villagrán y Castro 2004 \\
\hline $\begin{array}{l}\text { Sysimbrium } \\
\text { phillipianum } \\
\text { ("Chuchar") }\end{array}$ & Tolar y Campo & $\begin{array}{l}\text { Forrajera, } \\
\text { sahumar }\end{array}$ & Pérez 2006 \\
\hline
\end{tabular}

Tabla 6: Usos actuales de las especies identificadas en Alero sin Cabeza.

Table 6: Current uses of identified species in Alero sin Cabeza.

Un aspecto que podemos agregar a esta posible ocupación recurrente del sitio, se relaciona con la articulación de datos etnobotánicos que uno de nosotros ha relevado en la localidad Punta de la Peña (curso medio del río Las Pitas). El análisis de entrevistas realizadas a contrapartes locales da cuenta de una distinción en la época del año en que ciertas especies leñosas son usadas; Rica-Rica (Acantholippia deserticola) es una leńa de verano, mientras que Tola (Parastrephia lucida), Tramontana (Ephedra breana), Añahua (Adesmia horrida) y Chacha (Parastrephia quadranqularis) son leñas de invierno (Aguirre 2009). Excepto Tramontana, el resto de las leñas de invierno, según categorías actuales, están presentes en las muestras arqueológicas estudiadas, lo mismo ocurre con la leña de verano Rica-Rica. Articular estos datos actuales con los generados luego del análisis antracológico, puede sugerir el empleo de leńas que permitieron la ocupación del sitio mayormente en épocas invernales. La distinción entre leñas de verano/invierno realizadas por los informantes locales están asociadas a caracteres biológicos de las mismas, por ejemplo, se han identificado aceites esenciales en tricomas glandulosos de Acantholippia spp. (Botta 1980; Caro 1982), mientras que varias especies del género Fabiana contienen productos resinosos (Barboza 
y Hunziker 1993). Se reconoce que las maderas que tienen resinas y aceites poseen mayor poder calorífico (Bueno Zárate 1987). Además, arbustos de Parastrephia sp., en pie, pueden llegar a medir $1 \mathrm{~m}$ de alto, generando una importante cantidad de masa de madera muerta factible de ser empleada como leña.

Estos datos que permitirían postular ocupaciones de invierno en Alero Sin Cabeza hacia los 3500 años AP desde la antracología adquieren sentido al considerar otra serie de evidencias consonantes que se estarían dando en este momento de la secuencia arqueológica de ANS, que implicarían una mayor duración de las ocupaciones de las que previamente se había establecido (Aschero y Hocsman 2011).

La muestra antracológica analizada comprende 5 especies (Adesmia horrida, Atriplex imbricata, Sysimbrium phillipianum, Acantholippia deserticola y Chuquiraga atacamensis) que se distribuyen espacialmente en las unidades vegetacionales Tolar y Campo, mientras que Parastrephia lucida se encuentra en las cercanías de los cursos de agua, Parastrephia quadrangularis es propia de los sectores de laderas de quebradas, y Fabiana punensis y Fabiana bryoides se registran ambas en el Tolar, y en el Pajonal y en los sectores de vega, respectivamente. Resalta, entonces, el papel del Tolar y Campo en la gestión de recursos leñosos, siguiéndole en orden de importancia los sectores inmediatos a la vega puneña y el Pajonal. Mencionábamos al comienzo de este trabajo que tanto el Tolar como el Campo corresponden a vegetación de tipo dispersa y de escasa cobertura principalmente en el caso de este último. Estas dos unidades se identifican tanto en el Sector de Fondo de Cuenca como en los Sectores Intermedios de la microrregión. La preponderancia de recursos combustibles asociados al Tolar y a la vega puneña se entendería por la ubicación espacial del sitio Alero Sin Cabeza, que se sitúa dentro de la unidad vegetacional del Tolar y muy cercano al río Miriguaca, a $250 \mathrm{~m}$ en línea recta. Esto denotaría la explotación de recursos vegetales del entorno inmediato al sitio, lo cual está por cierto de acuerdo con las evidencias logradas para la micro-región en cuanto a ocurrencia de movilidad residencial reducida hacia los 3500 AP (Aschero y Hocsman 2011).

Los resultados del análisis antracológico posicionan a Adesmia sp. como el taxón mejor representado. Actualmente, ésta es considerada una buena leña en el área, mientras que Parastrephia sp., catalogada como la mejor leña según datos etnobotánicos (Aguirre 2009), tiene una representación muy baja, $6,83 \%$ en los carbones concentrados y $3,12 \%$ en los dispersos, en el registro analizado. 
La preponderancia de Adesmia sp. por sobre Parastrephia sp. está registrada además en otros sitios de cazadores-recolectores transicionales del área, como Quebrada Seca 3 (Rodríguez 2004a) o Peñas Chicas 1.3 (Aguirre 2007), localizados en el Pajonal y en el Tolar, respectivamente. La ubicuidad y mejor representación de este taxa en los sitios del área puede ser explicada teniendo en cuenta que Adesmia constituye un género frecuente para el área e igualmente útil como combustible mientras que Parastrephia sp. es una leña muy buena pero que tiene una representación menor en la zona, en base a datos actuales. Por otra parte, la identificación de Adesmia horrida es reiterada también en las inmediaciones del sitio. Teniendo esto en cuenta, se puede plantear un uso de recursos leñosos ubicados en las inmediaciones de la ocupación residencial con la incorporación, además, de recursos ubicados en sectores algo más alejados, aunque con distancias que no excederían los 7 $\mathrm{km}$. No debe dejar de mencionarse la posibilidad de una presión antrópica sobre las tolas, por sus muy buenas propiedades como leńa, lo que pudo derivar en una sobre-explotación de dichos recursos.

De todas formas, Adesmia sp. es un buen combustible que pudo ser complementado con otros recursos resinosos y aromáticos (Acantholippia ssp.) durante distintas estaciones del año y con fines diferentes, por ejemplo, iniciadores de fuego.

Si bien no hay hasta el momento evidencias polínicas para el área, los estudios paleoambientales denotan condiciones húmedas entre los 4500 y los 1600 años AP, y marcadamente húmedas hacia los 3500 años AP (Olivera et al. 2006; Tchilinguirian y Olivera 2009), momento de las ocupaciones consideradas de Alero sin Cabeza. Esto implicaría que las condiciones ambientales generales eran más favorables que hoy en día, con consecuencias positivas para la disponibilidad de recursos vegetales en general y leńosos en particular. Teniendo esto en cuenta, la baja representación en el registro antracológico de Parastrephia sp. y la ausencia en la muestra estudiada de las restantes dos especies que son consideradas actualmente las mejores leñas en ANS: Tramontana (Ephedra breana) y Lejía (Baccharis incarum) (Aguirre 2009), estaría relacionada a factores de índole social o tafonómico más que a los de tipo climático. En este sentido, puede mencionarse el estudio experimental llevado a cabo por Joly (2008) en la Puna de Jujuy, donde experimentó con la quema de Adesmia sp. cf "gruesa", Fabiana densa y Parastrephia lepidophylla. Los resultados obtenidos señalan que la primera especie alcanzó una temperatura mayor a los $300^{\circ} \mathrm{C}$ con una duración de 5 horas de combustión mientras que la segunda no superó los $100^{\circ} \mathrm{C}$ y las mediciones de temperatura se detuvieron luego de 5 horas de ensayos. 
En el caso de la tercera especie, esta logró una temperatura mayor a 400 ${ }^{\circ} \mathrm{C}$ pero una duración de combustión mucho menor $(2 \mathrm{~h} 10 \mathrm{~m})$. Estos datos animan a la autora a considerar a Adesmia sp. y a $P$. lepidophylla como los mejores combustibles frente a $F$. densa. Se reconoce que en el proceso de combustión intervienen diferentes tipos de factores, desde los relacionados con los criterios de selección de las especies a quemar, características físicoquímicas de las leñas hasta factores de tipo ambiental; por esto, los resultados generados por Joly (2008), pueden ayudar a entender las características del registro antracológico de Alero sin Cabeza. Así, la reacción diferencial de cada especie ante el fuego propuesta en el trabajo antes citado, estaría asociada a la conformación taxonómica de los fogones estudiados los cuales además son posteriormente afectados por distintos factores tafonómicos (pisoteo de animales, acción de agentes climáticos, reocupación del sitio, etc.) que continúan introduciendo modificaciones en los conjuntos de carbones preservados. Si bien las tolas tanto en la Puna de Jujuy como de Catamarca son consideradas como los mejores combustibles, la respuesta de las mismas ante el fuego es diferente a la respuesta de Adesmia sp.; así, esta última genera fuegos más duraderos que los de Parastrephia sp. Actividades domésticas de larga duración como ser cocción de alimentos, iluminación o calor, requieren de leñas que generen fuegos de larga duración. En vinculación con esto, pueden considerarse nuevas formas de cocción de comidas, que podrían estar presentes en estos momentos en el área, como el hervido, vinculadas con el consumo de recursos vegetales cultivados (Aschero y Hocsman 2011, Babot et al. 2012), o la necesidad de generar calor ante ocupaciones invernales, posibilidad tratada en este trabajo. Además, debe tenerse en cuenta que la buena representación de Adesmia en el registro analizado puede relacionarse también con la inmediatez espacial del recurso y con mayores volúmenes empleados de esta leña, como ya fue mencionado.

Por otra parte, destacan las frecuencias de recursos leñosos de calidad regular a buena como combustible en las muestras analizadas. Por ejemplo, en los carbones concentrados, Fabiana sp. comprende un 22,67\% y Acantholippia sp. un 15,33\% y en los carbones dispersos, 6,94\% y 16,46\%, respectivamente; es decir, tienen una importancia relativa considerable lo cual refuerza particularmente en el caso del último taxón, la importancia del mismo como indicador de una ocupación anual del sitio.

Esto lleva a plantear como posibilidad, una alternativa a la propuesta previa, ante el hecho de una baja representación de recursos leñosos combustibles de alta calidad y el papel de un recurso de buena calidad como Adesmia sp. que es complementado con otros taxa. $\mathrm{Al}$ respecto, se sugiere 
que la situación de movilidad residencial reducida y de un eventual semisedentarismo, involucrando ocupaciones invernales, podría haber llevado a una sobre-explotación de la leña de mejor calidad. A esto se suman las evidencias de territorialidad en el área hacia los 3500 años AP desde distintas líneas de evidencia (Aschero y Hocsman 2011), lo que habría llevado a una imposibilidad de acceder a recursos combustibles de otros sectores del área; dicha "circunscripción" espacial podría haber llevado a usar sistemáticamente ciertos recursos y a utilizar un espectro de leñas de menor calidad pero localmente disponibles, aún con condiciones ambientales favorables.

En suma, se destaca el empleo de combustibles locales durante esta ocupación del sitio; así, los recursos propios del área pudieron sustentar las necesidades de subsistencia cotidiana de quienes ocuparon Alero sin Cabeza. En cuanto al abastecimiento de combustibles, los resultados obtenidos motivan a sostener la recolección principalmente de leña muerta, es decir en el uso de la poda natural de las plantas, ya que para este sitio no hemos identificado restos de carbón de raíces en la muestra antracológica.

\section{Consideraciones finales}

La articulación del conocimiento sobre la distribución espacial actual de la flora en la micro-región y los datos generados en el análisis antracológico lleva a plantear que durante las ocupaciones cazadoras-recolectoras transicionales del sitio se realizaron recolecciones en las inmediaciones del mismo al mismo tiempo que se llevaron a cabo recolecciones de leña en sectores algo más lejanos.

La productividad, en cuanto a recursos leñosos de los Sectores Intermedios ha sido evaluada como media a alta (Olivera 2006), por lo que el sitio se encuentra emplazado en un sector óptimo de la micro-región donde las plantas leñosas son abundantes. Las especies identificadas en el registro antracológico de Alero sin Cabeza pueden considerarse tanto como recursos naturales, por desarrollarse en el entorno natural, y como recursos sociales, ya que fueron sistemáticamente incorporadas a actividades sociales en una época y lugar específicos (Mameli 2003).

Teniendo en cuenta que el objetivo inicial de este trabajo era explorar el aprovisionamiento de las materias primas leñosas en el marco de las estrategias de gestión de recursos leñosos, se puede decir que el uso del Tolar y Campo como espacios principales de aprovisionamiento leñoso se articuló con espacios más alejados, como el Pajonal, por ejemplo. Esta relación con 
el paisaje leñoso conllevó muy posiblemente modificaciones del mismo desde el momento en que ciertas especies comenzaron a ser reiteradamente utilizadas.

$\mathrm{Al}$ respecto, es muy posible que lo que estaba ocurriendo en el área en cuanto a los procesos de cambio socio-económicos de cazadores-recolectores a sociedades agro-pastoriles, con implicancias sobre la movilidad residencial, territorialidad y duración de las ocupaciones (Aschero y Hocsman 2011), tuvieron un correlato sobre la utilización de los recursos leñosos como combustible. Los datos obtenidos se articularían en este sentido, aunque es necesario profundizar las investigaciones. Aún así, el estudio presentado ejemplifica cómo un análisis antracológico, a modo de línea de evidencia independiente, aporta nueva información sobre los procesos de cambio o estabilidad en grupos humanos pasados. Asimismo, se destaca en este trabajo la importancia de procesar, ante la ausencia de estructuras concretas de combustión, distintos tipos de carbones como en este caso tanto los concentrados como los dispersos.

Agradecimientos: a la memoria de dońa Jacoba Morales, por su ayuda y conocimientos brindado en el registro de las plantas de ANS (M.G.A.). A Marisa López Campeny, Andrés Romano, Alvaro Martel, Carolina Somonte, Leticia Gasparotti y Lucas Ghecco por su ayuda inestimable en las excavaciones de ASC. Este trabajo se desarrolló en el marco del Proyecto 02/ A228 (UNCa), dirigido por P. Escola y el Proyecto PIP-CONICET 6398, dirigido por C. Aschero.

\section{Bibliografía}

Aguirre, M. G. 2007. "Arqueobotánica del sitio Peñas Chicas 1.3 (Antofagasta de la Sierra, Catamarca, Argentina)". En Paleoetnobotánica del cono sur: estudios de casos y propuestas metodológicas, compilado por B. Marconetto, M. P. Babot, y N. Oliszewski, pp: 179-195. Museo de Antropología FF y H. Universidad Nacional de Córdoba, Córdoba.

2009. "Conocimiento y uso de los recursos leñosos en la Puna meridional argentina”. Actas de las III Jornadas de Jóvenes Investigadores UN T. Versión CD-ROM (sin paginación). San Miguel de Tucumán, Argentina.

— 2012. Recursos Vegetales: Uso, Consumo y Producción en la Puna Meridional Argentina (5000-1500 AP). Tesis para optar al grado académico de Doctor en Ciencias Naturales, Facultad de Ciencias Naturales y Museo, Universidad Nacional de La Plata. 
Allué, E. y D. García Antón. 2006. "La transformación de un recurso biótico en abiótico: aspectos teóricos sobre la explotación del combustible leñoso en la prehistoria”. En Sociedades prehistóricas, recursos abióticos y territorio. III Reunión de trabajo sobre aprovisionamiento de recursos abióticos en la prehistoria, editado por G. Martínez Fernández, A. Morgado Rodríguez y J. A. Afonso Marrerotores, pp: 19-31. Fundación Ibn al-Jatib de Estudios de Cooperación Cultural, Loja.

Ancibor, E. y C. Pérez de Micou. 2002. "Reconocimiento de especies vegetales combustibles en el registro arqueológico de la estepa patagónica”. En Plantas y cazadores en Patagonia, compilado por C. Pérez de Micou, pp: 15-32. FFyL, UBA, Buenos Aires.

Aschero, C. A. 2006. "De cazadores y pastores. El arte rupestre de la modalidad Río Punilla en Antofagasta de la Sierra y la cuestión de la complejidad en la Puna meridional argentina". En Tramas en la piedra. Producción y usos del arte rupestre, editado por D. Fiore y M. Podestá, pp: 103-140. World Archaeological Congress, Sociedad Argentina de Antropología, Asociación de Amigos del Instituto Nacional de Antropología, Buenos Aires.

Aschero, C. A., L. Manzi y A. Gómez. 1993-1994. "Producción lítica y uso del espacio en el nivel 2b4 de Quebrada Seca 3". Relaciones de la Sociedad Argentina de Antropología 19: 191-214.

Aschero, C. A., P. S. Escola, S. Hocsman y J. G. Martínez. 2002-2004. "Recursos líticos en escala microrregional. Antofagasta de la Sierra 19832001". Arqueología 12: 9-36.

Aschero, C. A. y S. Hocsman. 2011. "Arqueología de las ocupaciones cazadorasrecolectoras de fines del Holoceno Medio de Antofagasta de la Sierra (Puna Meridional Argentina)". Chungara. Revista de Antropología Chilena. 43(1): 393-411

Asouti, E. y J. Hather. 2001. "Charcoal analysis and the reconstruction of ancient woodland vegetation in the Konya Basin, south-central Anatolia, Turkey: results from the Neolithic site of Çatalhoyuk East". Vegetation History and Archeobotany 10: 23-32.

Babot, M. P. 2004. Tecnología y Utilización de Artefactos de Molienda en el Noroeste Prehispánico. Tesis para optar al grado académico de Doctor en Arqueología, Facultad de Ciencias Naturales e Instituto Miguel Lillo, Universidad Nacional de Tucumán.

Babot, M. P., S. Hocsman, R. E. Piccón Figueroa y M. C. Haros. 2012. "Recetarios prehispánicos y tradiciones culinarias. Casos de la Puna Argentina”. En Las manos en la masa. Arqueologias y antropologías e historias 
de la alimentación en Suramérica, editado por M. P. Babot, M. Marschoff y F. Pazzarelli, pp: 235-269. Corintios, Córdoba.

Badal, E., Y. Carrión, D. Rivera y P. Uzquiano. 2003. "La arqueobotánica en cuevas y abrigos: objetivos y métodos de muestreo". En La recogida de muestras en arqueobotánica: objetivos y propuestas metodológicas. La gestión de los recursos vegetales y la transformación del paleopaisaje en el Mediterráneo Occidental, coordinado por R. Buxó y R. Piqué, pp: 19-30. Museu d'Arqueologia de Catalunya, Barcelona.

Barboza, G. E. y A. T. Hunziker. 1993. "Estudios en Solanaceas XXXIV revisión taxonómica de Fabiana”. Kurtziana 22: 109-153.

Berihuete Azorín, M. y R. Piqué. 2006. “Semillas, frutas, leña, madera: el consumo de plantas entre las sociedades cazadoras-recolectoras". Revista Atlántica Mediterránea de Prehistoria y Arqueología Social 8: 35-51.

Botta, S. M. 1980. "Las especies del género Acantholippia (Verbenaceae)". Darwiniana 22(4): 511-532.

Bravo, S., A. M. Jiménez, C. Kunst y G. Moglia. 2003. "El fuego y las plantas”. En Fuego en los ecosistemas argentinos, editado por C. Kunst S. Bravo y J.L. Panigatti, pp: 61-70. INTA, Buenos Aires.

Bueno Zárate, J. 1987. “Las maderas como combustible”. Revista Forestal del Perú 14(2): 1-9.

Blarquez, O. y C. Carcaillet. 2010. "Fire, fuel composition and resilience threshold in subalpine ecosystem". PLoS ONE 5(8): 1-8.

Chabal, L. 1992. "La représentativité paléo - écologique des charbons de bois archaéologiques issus du bois de feu”. Bulletin de la Société Botanique de France Actualités Botanique 139: 213-236.

Caro, J. A. 1982. "Sistematización del género Acantholippia Grisebach (Verbenaceae) y las especies de la flora argentina”. Dominguezia 3: 1-17.

Castro, M. A. 2002. "Anatomía vegetal y arqueología". En Plantas y cazadores en Patagonia, compilado por C. Pérez de Micou, pp: 89-103. Facultad de Filosofía y Letras, UBA, Buenos Aires.

Conedera, M., W. Tinner, C. Neff, M. Meurer, A. F. Dickens y P. Krebs. 2009. Reconstructing past fire regimes: methods, applications, and relevance to fire management and conservation". Quaternary Science Reviews 28 (5-6): 435-456.

Cuello, A. S. 2006. Guía Ilustrada de La Flora de Antofagasta de la Sierra Catamarca (Puna Meridional Argentina). Curso de entrenamiento para la 
obtención del grado de Licenciatura en Ciencias Biológicas (orientación Botánica). Facultad de Ciencias Naturales e IML, Universidad Nacional de Tucumán, Tucumán.

Euba Rementeria, I. 2008. Análisis Antracológico de Estructuras Altimontanas en el Valle de la Vansa-sierra del Cadi (Alt Urgell) y en el Valle del Madriu (Andorra): Explotación de Recursos Forestales del Neolitico a Epoca Moderna. Tesis para optar al grado académico de Doctor. Departament d'Història i Història de l’Art, Universitat Rovira i Virgili, Tarragona.

Fahn, A. 1974. Anatomía Vegetal. H. Blume Ediciones. Madrid.

Grau, E. 1992. "Méthodologie de prélèvements des charbons de bois dans les sites protohistoriques". Bulletin de la société botanique de France. Actualités Botaniques 139: 205-212.

Grant, M. y M. Waller. 2010. "Holocene Fire Histories from the Edge of Romney Marsh". En Romney marsh: persistence and change in a coastal lowland, editado por M. Waller E. Edwards y L. Barber, pp: 53-73. Romney Marsh Research Trust, Exeter.

Haber, A. 1992. "Pastores y pasturas. Recursos forrajeros en Antofagasta de la Sierra (Catamarca), en relación a la ocupación Formativa”. Shincal 2: 15-23.

Hocsman, S. 2002. “¿Cazadores-recolectores complejos en la Puna Meridional Argentina? Entrelazando evidencias del registro arqueológico de la microrregión de Antofagasta de la Sierra (Catamarca) ". Relaciones de la Sociedad Argentina de Antropología 27: 193-214.

— 2006. Producción Lítica, Variabilidad y Cambio en Antofagasta de la Sierra -ca. 5500-1500 AP. Tesis para optar al grado académico de Doctor en Ciencias Naturales, Facultad de Ciencias Naturales y Museo. Universidad Nacional de La Plata.

Jardón Giner, P. 1998. “El ser humano y el control del fuego”. En A la luz del hogar, coordinado por B. Soler Mayor y P. Jardón Giner, pp: 14-17. Collecció perfils del passat 3. Museu de Prehistòria. Valencia.

Jofré, I. C. 2007. "Estudio antracológico en Tebenquiche Chico (Dpto. Antofagasta de la Sierra, Provincia de Catamarca) ". En Paleoetnobotánica del cono sur: estudios de casos y propuestas metodológicas, compilado por B. Marconetto, M. P. Babot, y N. Oliszewski, pp: 153-178. Museo de Antropología FF y H. Universidad Nacional de Córdoba, Córdoba.

Joly, D. R. 2008. Etude de la gestion du combustible osseux et végétal dans les stratégies adaptatives des chasseurs-cueilleurs et des groupes agro-pastoraux 
d'Argentine durant l'Holocène. Tesis para optar al grado académico de Doctor de la Universidad de Rennes 1, Francia.

Joly, D. R. March D. Marguerie y H. Yacobaccio. 2009. "Gestion des combustibles dans la province de Jujuy (Puna, Argentine) depuis l'Holocène ancien: Croisement des résultats ethnologiques et anthracologiques". En Gestion des combustibles au Paléolithique et au mésolithique Nouveaux outils, nouvelles interprétations, editado por I. Théry-Parisot, I., S. Costamagno y A. Henry, pp : 39-56. BAR International series, Oxford.

Kahn, J. G. y J. Coil. 2006. "What house posts tell us about status difference in prehistoric tahitian society: an interpretation of charcoal analysis, sacred woods and inter-site variability". The Journal of the Polynesian Society 115(4): 319-352.

Latzina, E. 1937. “Calorimetría de maderas”. Lilloa 1: 235-248.

Mameli, L. 2003. La Gestión Del Recurso Avifaunistico Por Las Poblaciones Canoeras Del Archipiélago Fueguino. Tesis para optar al grado académico de Doctor, Universidad Autónoma de Barcelona, Barcelona.

Mc Parland, L. C., M. E. Collison, A. Scott, G. Campbell y R. Veal. 2010. "Is vitrification in charcoal a result of high temperature burning of wood? ”. Journal of Archaeological Science 37(10): 2679-2687.

March, R. J. y J. C. Ferreri. 1989. "Sobre el estudio de estructuras de combustión arqueológicas mediante replicaciones y modelos numéricos”. En Nature et fonction des foyers préhistoriques, Actes du colloque international de Nemours (1987), dirigido por M. Olive y M. Taborin, pp: 59-68. Mémoires du Musée de Préhistoire d'Île-de-France 2, A.P.R.A.I.F., Nemours.

March, R. J., A. Baldessari, J. C. Ferreri, A. Grande, E. G. Gros, O. Morello y R. Rodano. 1991. "Étude des structures de combustion archéologiques d'Argentine”. Bulletin de la Société Préhistorique Française 86 (10-12): 384392.

March, R. J. y G. Wünsch. 2003. "Loupes et lentilles obscures: A propos de la fonction des structures de combustion". En Le feu domestique et ses structures au Néolithique et aux âges des métaux, editado por M. Mergoil, pp: 311-318. Bourg-en-Bresse et Beaune, Francia.

Marconetto, M. B. 2005. Recursos Forestales y El Proceso de Diferenciación Social en Tiempos Prehispánicos en el Valle de Ambato, Catamarca. Tesis para optar al grado académico de Doctor en Ciencias Naturales, Facultad de Ciencias Naturales y Museo, Universidad Nacional de La Plata. 
2010. "Paleoenvironment and anthracology: determination of variations in humidity based on anatomical characters in archealogical plant charcoal (Ambato Valley, Catamarca, Argentina) ". Journal of Archaeological Science 37(6): 1186-1191.

Olivera, D. E. 1992. Tecnología y Estrategias de Adaptación en el Formativo (AgroAlfarero Temprano) de la Puna Meridional Argentina. Un Caso de Estudio: Antofagasta de la Sierra (Pcia. de Catamarca, R.A.). Tesis para optar al grado académico de Doctor en Ciencias Naturales, Facultad de Ciencias Naturales y Museo, Universidad Nacional de La Plata.

2006. "Recursos bióticos y subsistencia en sociedades agropastoriles de la Puna Meridional Argentina". Comechingonia 9: 19-55.

Olivera D.y D. Elkin. 1994. "De cazadores y pastores: el proceso de domesticación de camélidos en la Puna Meridional Argentina”. En Zooarqueología de camélidos 1, editado por Grupo de Zooarqueología de Camélidos-GZC, pp: 95-124. Ediciones del Tridente, Buenos Aires.

Olivera, D. E.; P. Tchilinguirian y M. J. de Aguirre. 2006. "Cultural and environmental evolution in the meridional sector of the Puna of Atacama during the Holocene". En Change in the Andes: Origins of social complexity, pastoralism and agriculture, coordinado por H. Yacobaccio y D. Olivera, pp: 7-15. BAR International Series 1524, Oxford.

Pérez, E. L. 2006. Las Plantas Utilizadas por la Comunidad de Antofagasta de la Sierra, Puna Catamarqueña, Argentina. Curso de entrenamiento para la obtención del grado de Licenciatura en Ciencias Biológicas (orientación Botánica). Facultad de Ciencias Naturales e IML, Universidad Nacional de Tucumán.

Piqué i Huerta, R. 1999. Producción y Uso de Combustible Vegetal Arqueológico: Una Evaluación Arqueológica. Treballs d'Etnoarqueología 3. Universidad Autónoma de Barcelona, Barcelona.

Piqué i Huerta, R. y J. M. Piqué i Huerta. 1991. "Aplicación del tratamiento de imágenes digitalizadas al análisis antracológico: un ensayo de determinación automática”. En Arqueología: Nuevas tendencias, coordinado por A. Vila, pp: 115-129. Consejo Superior de Investigaciones Científicas, Madrid.

Prior J.y K. Alvin. 1983. "Structural changes on charring woods of Dichrostachys and Salix from southern Africa”. IAWA Bulletin 4 (4): 197-206.

Rodríguez, M. F. 1999. "Plant species at an archaeological site of the Southern Argentina Puna (Families: Poaceae, Asteraceae, Fabaceae and Solanaceae)”. Journal of Ethnobiology 19 (2): 228 - 247. 
— 2000. "Woody plant species used during the Archaic period in the Southern Argentine Puna. Archaeobotany of Quebrada Seca 3". Journal of Archaeological Science 27 (4): 341 - 361.

2004a. "Cambios en el uso de los recursos vegetales durante el Holoceno en la Puna meridional argentina". Chúngara. Revista de Antropología Chilena (Volumen especial): 403-413.

— 2004b. "Woody plant resources in the Southern Argentine Puna. Punta de la Peña 9 archaeological site”. Journal of Archaeological Science 31 (10): 1361-1372.

Scott, A. C. y F. Damblon. 2010. "Charcoal: Taphonomy and significance in geology, botany and archaeology”. Palaeogeography, Palaeoclimatology, Palaeoecology 291(1-2): 1-10.

Solari, M.E. 2007. “Discusiones en torno a la antracología y los sitios arqueológicos de la región sur-austral de Chile”. En Paleoetnobotánica del cono sur: estudios de casos y propuestas metodológicas, compilado por B. Marconetto, M. P. Babot, y N. Oliszewski, pp: 127-135. Museo de Antropología FF y H. Universidad Nacional de Córdoba. Córdoba.

Soler Mayor, B. 2003. Estudios de las Estructuras de Combustión Prehistóricas: Una Aproximación Experimental. Cova Negra (Xàtiva, Valencia), Ratlla del Bubo (Crevillent, Alicante) y Marolles-sur-Seine (Bassin Parisien, Francia). Servicio de Investigación Prehistórica, Diputación Provincial de Valencia, Valencia.

Scheel-Ybert, R. 2004. “Teoria e método em antracologia. i: considerações teóricas e perspectivas". Arquivos do Museu Nacional Rio de Janeiro 62(1): 3-14.

Tchilinguirian, P. y D. E. Olivera. 2009. "Paleoambientes y geoarqueología: Sitios Corral Grande y Arroyo Las Pitas. Antofagasta de la Sierra (Prov. de Catamarca, Puna Meridional Argentina) ”. En Arqueometría Latinoamericana $2^{\circ}$ Congreso Argentino y $1^{\circ}$ Latinoamericano, editado por O. Palacios, C. Vázquez, T. Palacios y E. Cabanillas, pp: 544-551 (Volumen 2). CONEA y Universidad de San Martín, Buenos Aires.

Troll, C. 1958. "Las culturas superiores andinas y el medio geográfico". Revista del Instituto de Geografía 5: 3-55.

Villagrán, C. y V. Castro. 2004. Ciencia Indigena de los Andes del Norte de Chile. Editorial Universitaria, Santiago de Chile.

Villagrán, C., V. Castro, G. Sánchez, M. Romo, C. Latorrey L. Hinojosa. 1998. "La tradición surandina del desierto: etnobotánica del área del salar de 
Atacama (Provincia de El Loa, región de Antofagasta, Chile) ”. Estudios Atacameños 16: 7-105.

Whitlock, C. y P. J. Bartlein. 2003. "Holocene fire activity as a record of past environmental change". Development in Quaternary Science 1: 479-490.

Willis, K. J., K. D. Bennett y S. G. Haberle. 2008. "Solar influence on Holocene fire history". En Charcoals from the Past: Cultural and palaeoenvironmental implications. Proceedings of the Third International Meeting of Anthracology, Cavallino - Lecce (Italy) (2004), editado por G. Fiorentino y D. Magri, pp: 307-318. BAR International Series 1807, Oxford.

Yacobaccio, H. 1994. "Biomasa animal y consumo en el Pleistoceno-Holoceno Surandino”. Arqueología 4: 43-71. 